\title{
دور الحركة في التصميم الزخرفي ثلاثي الأبعاد
}

\author{
إعلداد \\ غادة حمدي المنجحسـ خليلــ \\ طالبة بمرحلة الماجستير بقسم التربية الفنية \\ كلية التربية النوعية ـ جامعة المنصورة \\ تحت إشراف

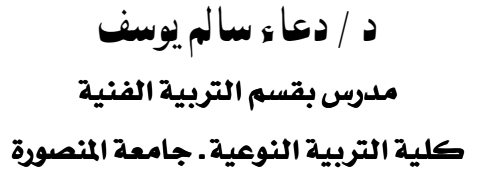 \\ هد / دعاء سالم يوسف \\ مدرس بقسم التربية الفنية \\ كلية التربية النوعية ـ جامعة المنصورة
}

مجلة بحوث التربية النوعية ـ جامعة المنصورة

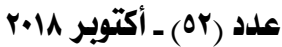




\title{
دور الحركة في التصميم الزخرفي ثلاثي الابعاد
}

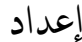 \\ مد / دعاء سالميوسف \\ أ . أد / محمد إبراهيمرجب الشوربكجمـ \\ غادة حمدي المنجج خليل
}

aغil|

استهدف البحث اهتهمام الفنانون بالعمل علي التكامل والشكل بحيث يدخل الفراغ كهنصر

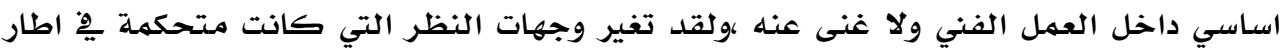

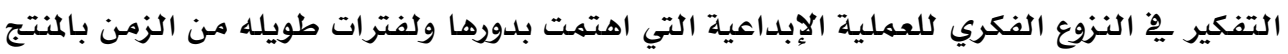

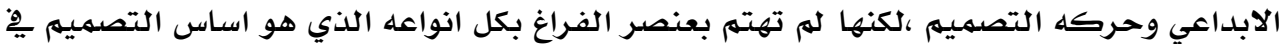

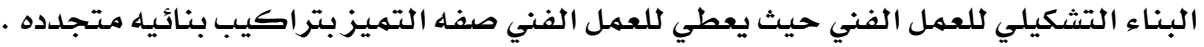

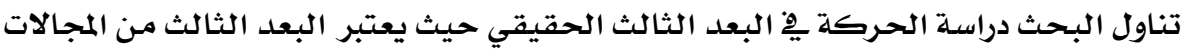

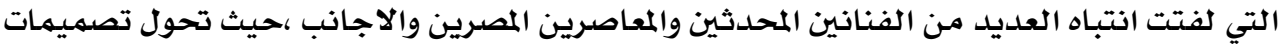

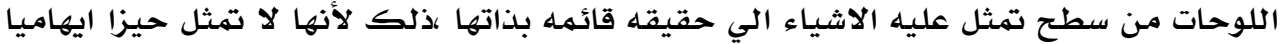

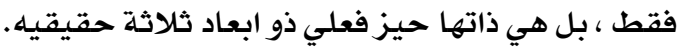
وتوصل البحث الى نتائج هامـة ِِّ مجال التصميم الزخريٌ المستخدم فيه البعد الثالث

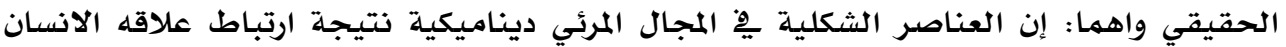

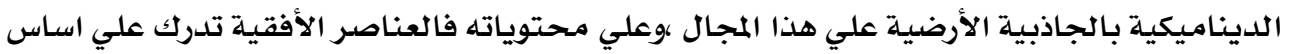

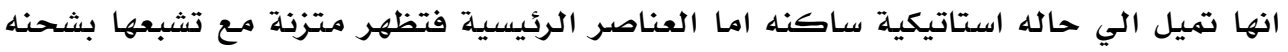

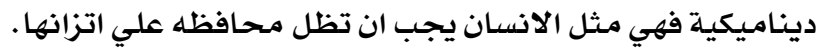

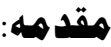

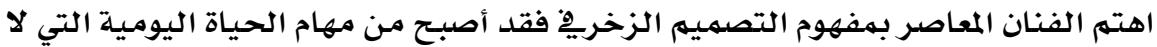

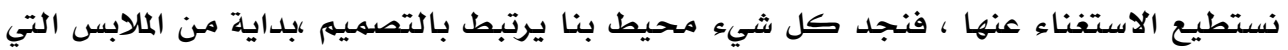

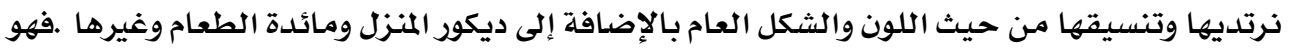

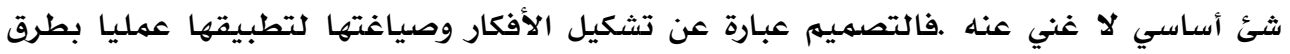

" أستاذ النحت ورئيس قسم التربية الفنية - كلية التربية النوعية - جامعة المنصورة

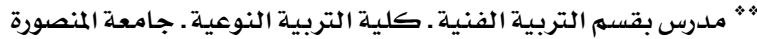

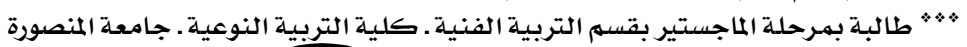


مستحدثة حسب وجهة نظر كل فنان فصياغة جميع الجوانب المتعلقة بهذه الفكرة ووضع تصور

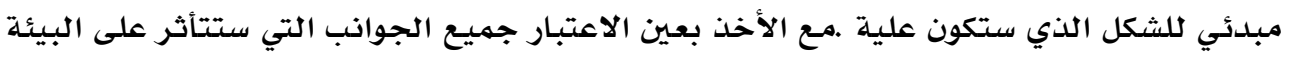

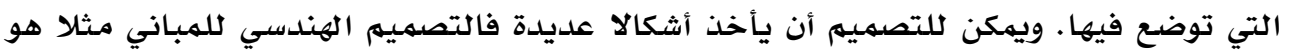

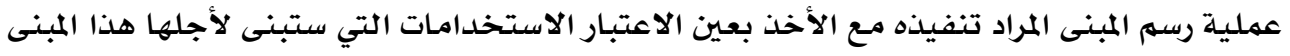

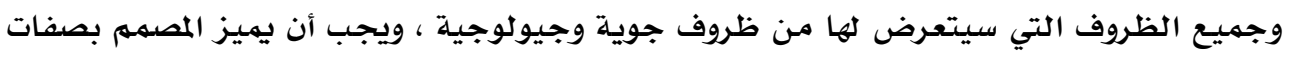

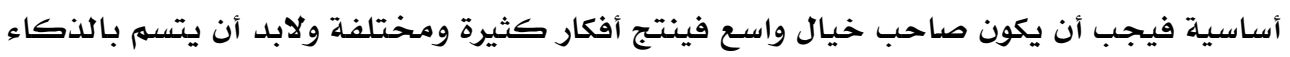

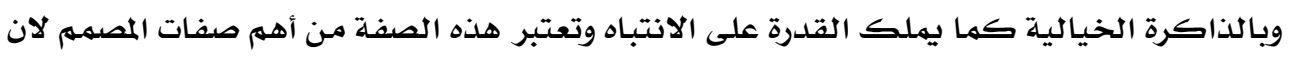

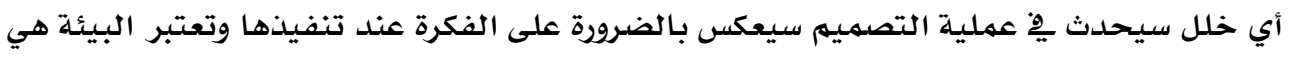

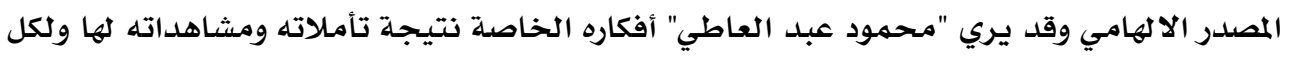

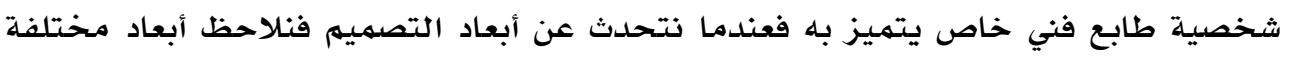

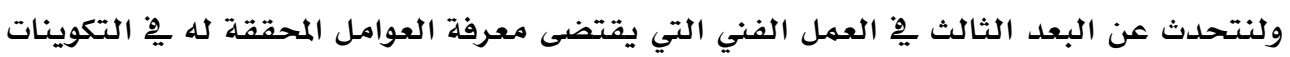

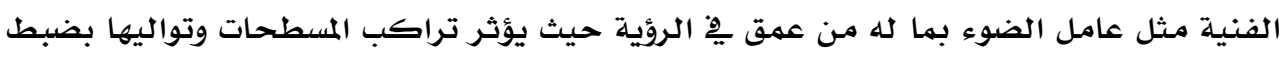

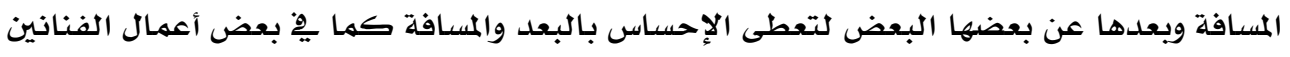

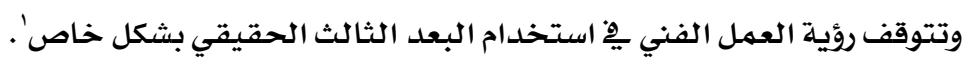

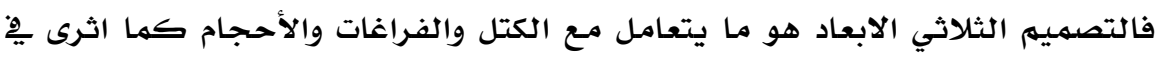

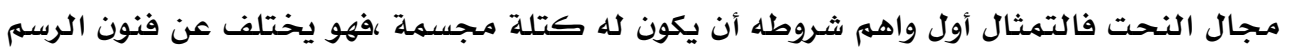

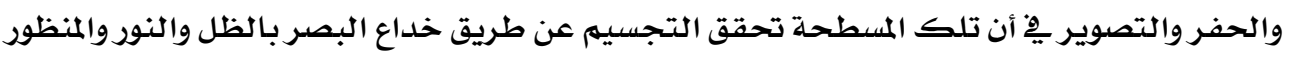

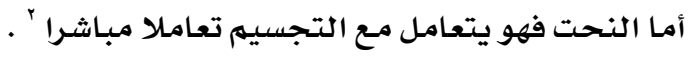

وقد تنوعت وتعددت أشكال العلاقة بين التسطيح والتجسيه وكشفت عن مراحل إفاقة

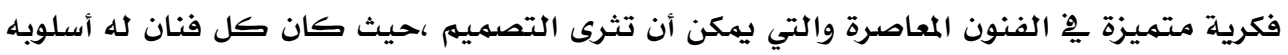

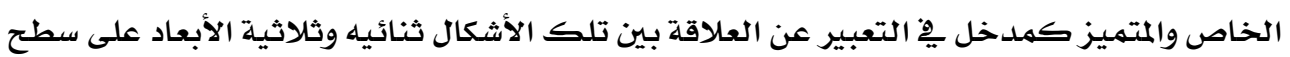

وما كنا نعيث مِّ عالم ثلاثي الأبعاد فان ما نراه أمامنا ليس بهيئة مسطحة ذات طول

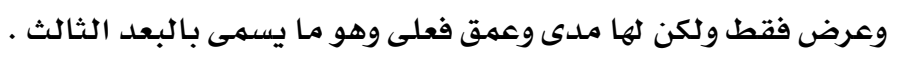

فقد يمر المصمم بقوانين حيث يستمدل استخلاص النظم من الطبيعة والتعرف علي النسبـة

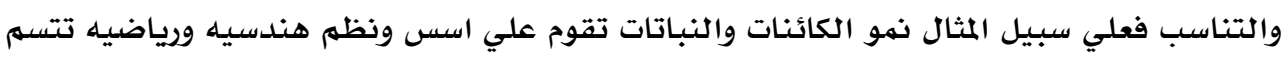

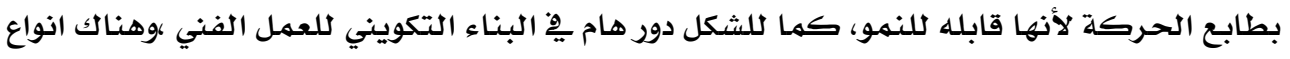
1 محممود عبد العاطى ."(توظيف البعد الثالث الحقيقي يِ التصوير الحديث")دراسة تجريبية دراسة دكتوره غير منشوره

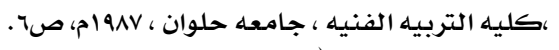

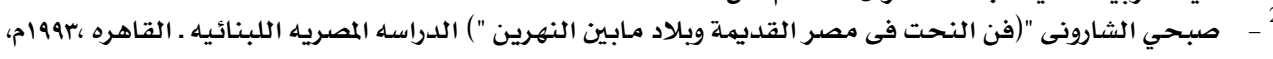
"طارق احمد البهي "(الإمكانات التشكيلة للأشكال ثنائية وثلاثية الأبعاد يِّ الفن التجريبي كمصدربلاثراء التصميم 


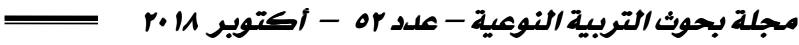

كثيره من الاشكال والهيئات ِِّ الطبيعة تتسهم بالتنوع والتناسب والتوازن والانتظام وتعد من

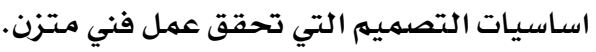

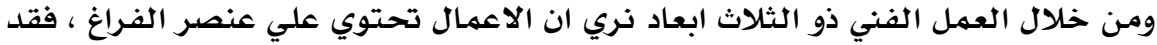

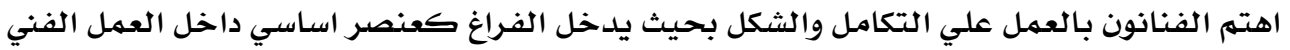

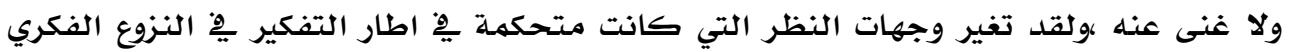

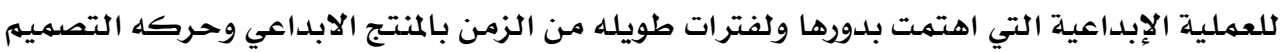

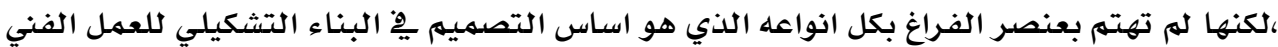

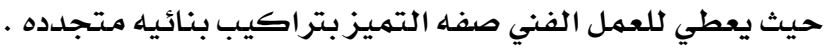

ويعتبر البعد الثالث من المجالات التي لفتت انتباه العديد من الفنانين المحلدثين

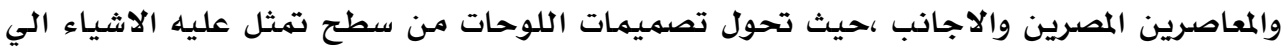

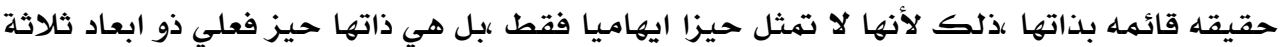
حقيقيه ' حقيقه

وقد لجآ الباحثين الي توظيف البعد الثالث ِِّ اعما لهم الفنية كضرورة بنائيه استهـافا

للتأثير يِّ المثاهد والعمل علي تغير انهاطه التذوقية مما يجلع يقوم بعمليه التخمـين والتوقع ..

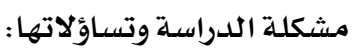

\section{وِِِ ضوء العرض السابق يمكن تحديد مشكلة الدراسة ِِِ التساؤلات التالية:}

اـ ما امكانية تحقيق القيم الجمالية ِِّ اللوحة الزخرفية المستخدم فيها أساليب بناء تكوين

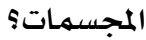

r ـ ما امكانية توظيف البعد الثالث الحقيقي علي مختارات من الفن ثلاثي الابعاد كقيمها

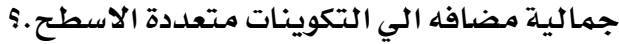

\section{أهميسة الدراسة:}

\section{تتضح أهمية الدراسة الحالية فِ النقاط التالية: .}

ا.الكثف عن إمكانية تنمية القدرة على التعامل مـع التصميمات بحرية اكبر لإيجاد حلول

$$
\text { تشكيلية جديدة ومبتكرة . }
$$

r. طرح أفكار جديدة ومبتكرة لإنتاج لوحة تصميمـه تحمل قيم جمالية معاصره .

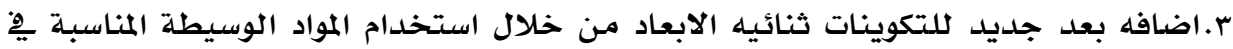

$$
\text { تشكيل التصميم ثلاثي الابعاد . بادل }
$$

1 (r) محمود عبد العاطي :"توظيف البعد الثالث الحقيقي يِّ التصوير الحديث "، دراسه تجريبيه ، رساله دكتوراه ،

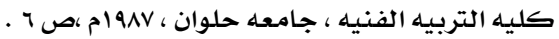


تتحلد أهداف الدراسة الحالية فيما يلي: . تحماف

ا ـ تحليل دور القيم الجمالية والتصميمية التي تقوم عليها الاعمال ذات البعد الثالث . r. إلقاء الضوء على الجوانب الجمالية للتصميم ثلاثي الابعاد وأهميتها ِِّ تحقيق الشخصية المتميزة للفنان

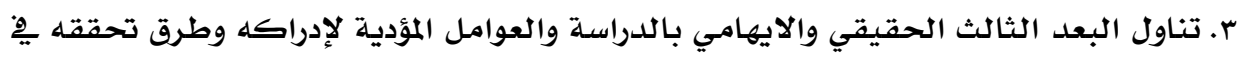

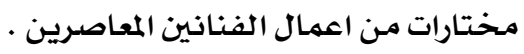

\section{فروض الدراسة:}

\section{تقترح الباحثة الفروض التالية: .}

ا. يمكن تحقيق القيم الجمالية ِِ اللوحة الزخرفية المستخدم فيها أساليب بناء تكوين

المجسمات.

$$
\text { r . يمكن توظيف البعد الثالث لإثراء التصميمات الزخرفية المجسمة . }
$$

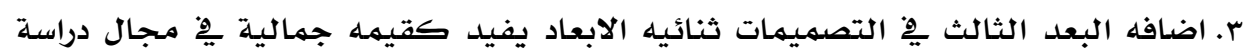

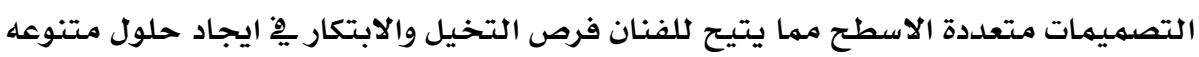

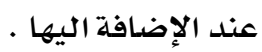

\section{هنهمج الدراسة:}

تعتمد الدراسة على المنهج الوصفي باعتباره أنسب المناهج التي تتفق وطبيعة هذه الدراسلة،

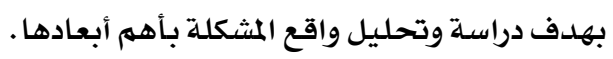

\section{الإطار النظري للدراسة:}

أولا: مفهوم البعد الثالث الايهامي :

يقصد بالبعد الثالث الايهامي تحقيق أشكال ذات البعد التقديري الذي نشا من خلال

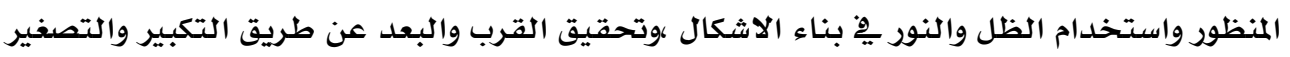

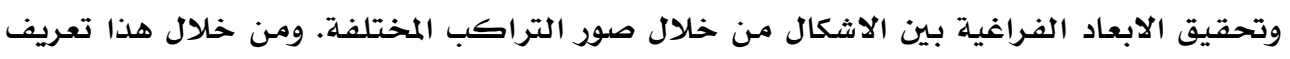

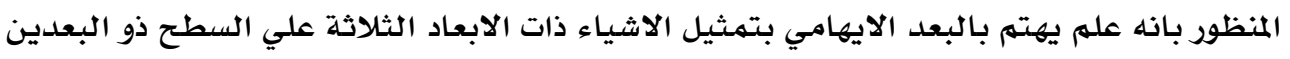

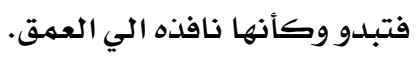

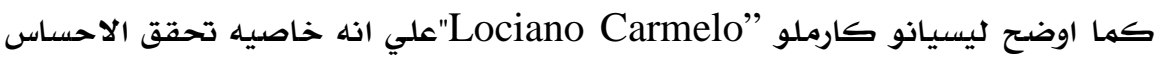

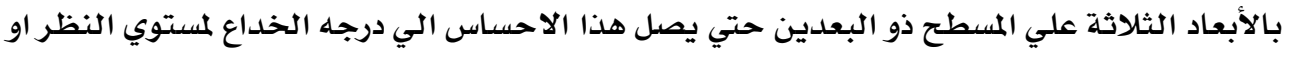

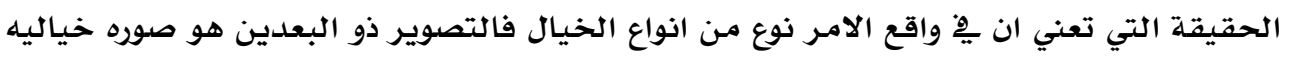

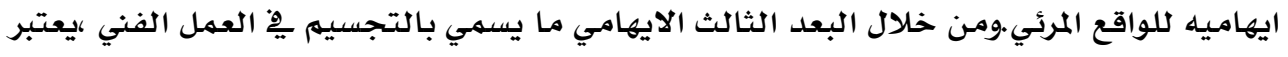


من المفاهيم التي مرت بتجارب عديده علي مدي حقبات التاريخ، فالفنان التشكيلي كان ذائم التمان التاني

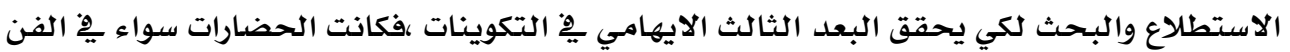

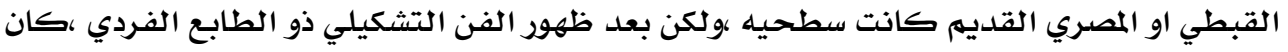

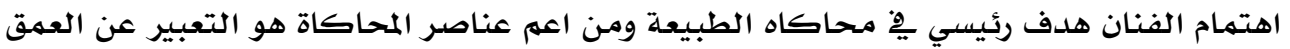

$$
\text { الثالث الايهامي للأثكال. }
$$

\section{ثانياً: عناصر التكوين في التصميي الثلاثي الابعاد:}

تستمد كافه العناصر التي نستخدمها يف اي عمل فني من البيئة الطبيعية التي هي مصدر

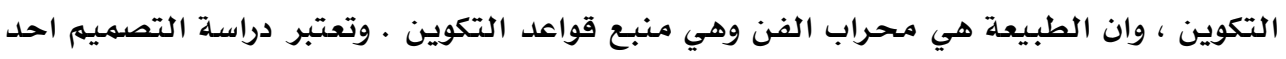

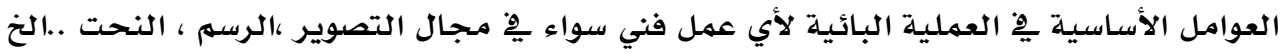

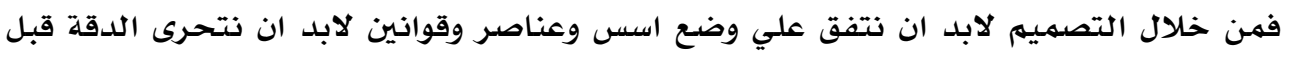
تنفيذها وكما يلي نعرض عناصر التصميهم يٌْ التكوين ثلاثي الابعاد :

Line r الخط

Shape الشكل

Space الفراغ

مـ اللون color
Dot 1. 1 النقطه

Area r. المساحهـ

$$
\text { Mass " الكتله "الحجهم }
$$

Texture الملمس

\section{ثالثاً: مفهوم عناصر التصميم الثلاثي الابعاد:}

" تعني كل ما يمكن رؤيته هِِ العمل الفني ، أو هو أصغر العناصر القابلة للتكرار والتبادل

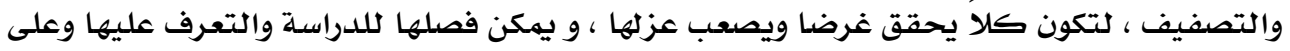

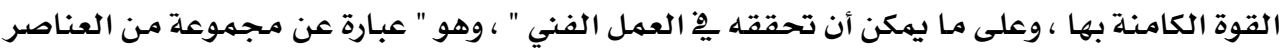

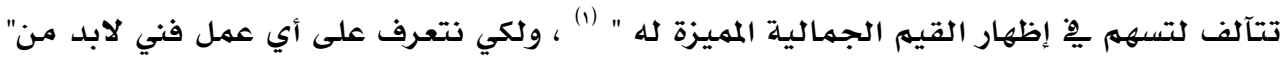

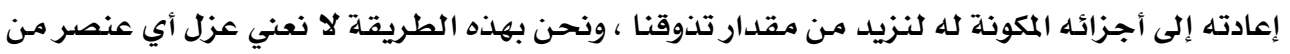

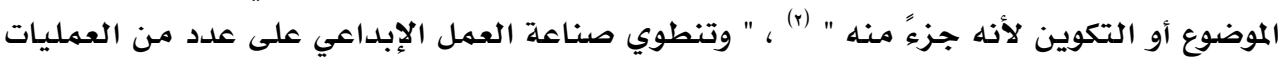

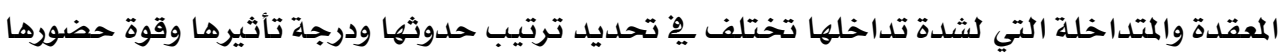

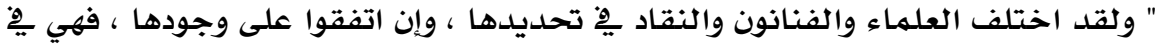

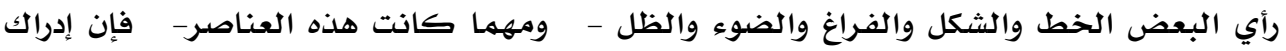

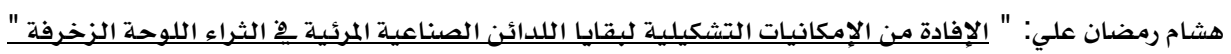

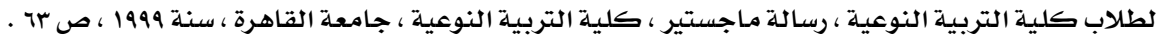

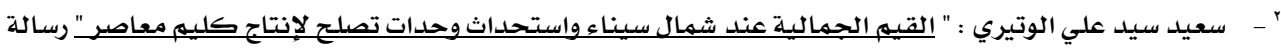

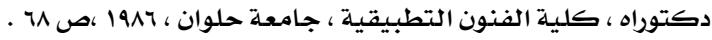

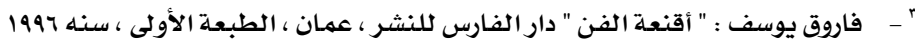


الفنان لها إدراكا جيدا يساعده يِّ عملية التخطيط ويجعل عمله سهلا طيعا ، كما يساعده فِ

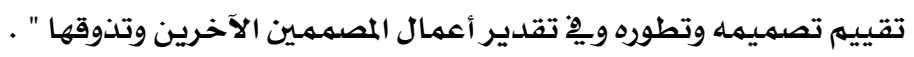

وهذه العناصر نجد أنها مترابطة لا يمكن تجزئتها ، و رغم ترابطها فهي تمتاز بخاصية

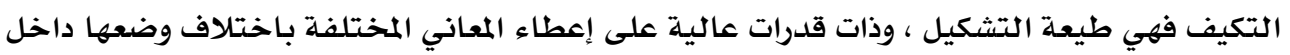

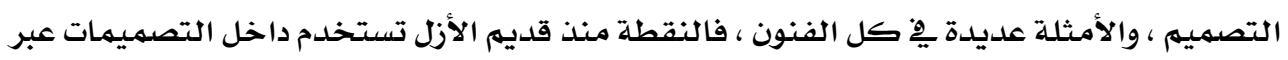

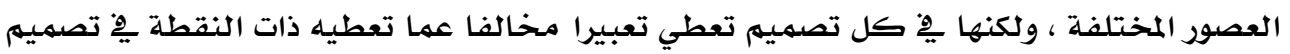

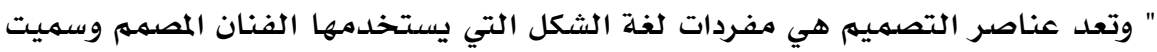

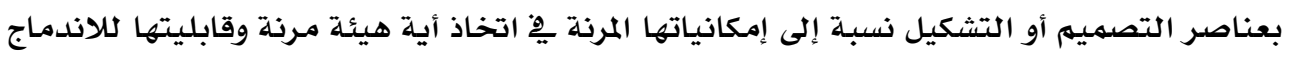
والتآلف والتوحد بعضها مـع بعض لتكون شكلا كليا للعمل الفني المصمَّم " .

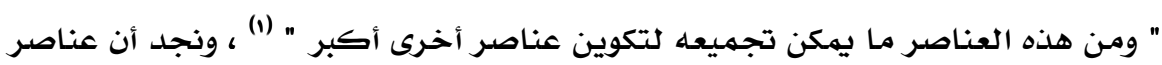

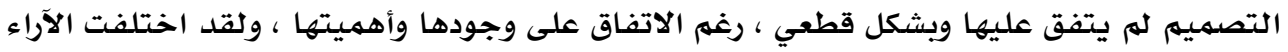

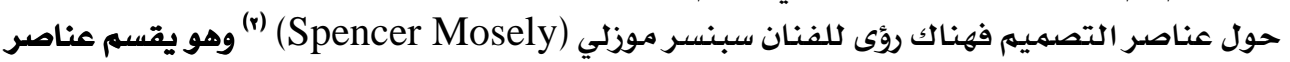
التصميم إلى :-

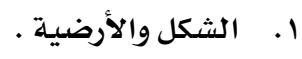

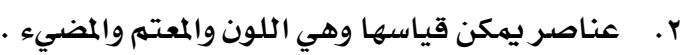

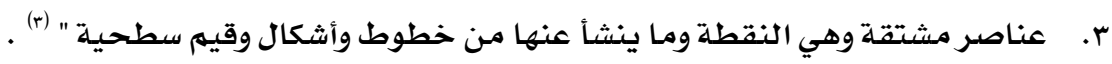

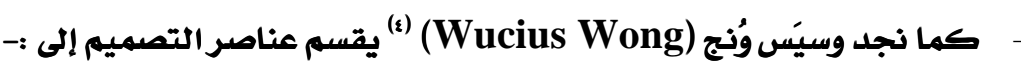

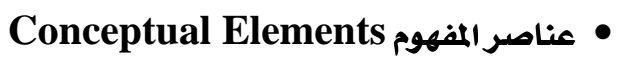

وهي النقطة - الخط- - المساحة - الكتلة.

• • العناصر البصرية وهي النقة

وهي الشكل - النسب - اللون - الملامس.

• عelational Elements عناصر الربط الشكل

وهي الإخراج - الفراغ - الطباعة .

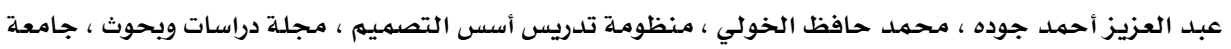

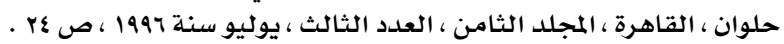

3 - Spencer Mosely and Others The Crafts design -ward swwarth publishing inc, Belmante California U .S .A .

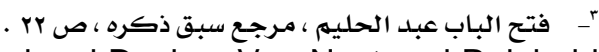

5 - Wucius Wong, Principles of Two - Dimensional Design, Van Nostrand Reinhold Company, New York, 1972, p7. 


\title{
Practical Elements العناصر العملية
}

$$
\text { وهي الموضوع والمدلول والوظيفة . }
$$

\section{• الإطار المرجعي وإوي}

\author{
وهو مساحة الصورة وبنيتها .
}

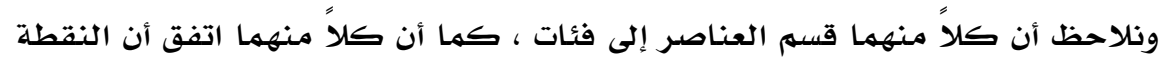

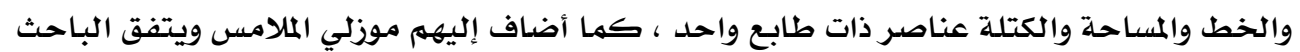

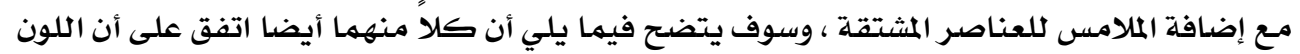

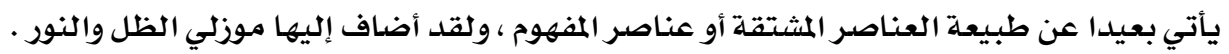

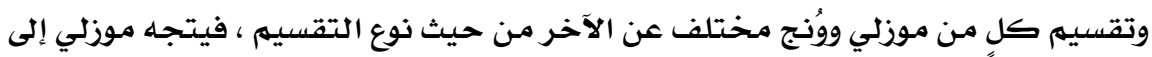

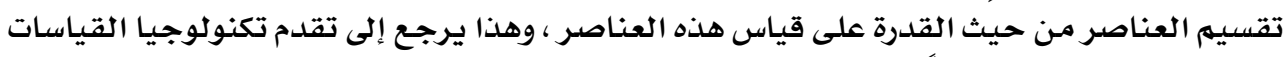

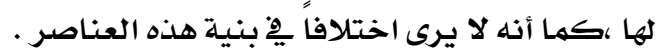

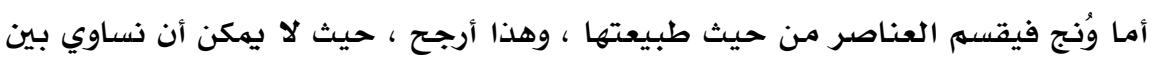

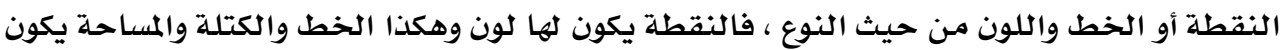

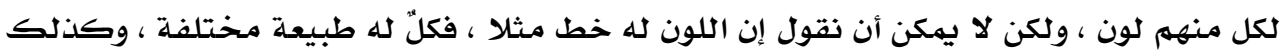

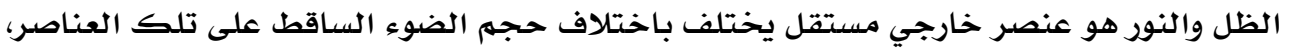

ويقوم بتأكيدها ويبرزها.

\section{ومما سبق يمكننا القول بأن عناصر التصميم تنقسم إلى :}

عناصر متسلسلة وهي ما أطلق عليها موزبي عناصر مشتقة ، أي أنها تشتق من بعضها البعض وسماها ونج

$$
\text { عناصر المفهوم . }
$$

وهي النقطة - الخط - المساحة - المعالجات الملمسية - الملامس - الكتلة

عناصر بصرية :

$$
\text { • عناصر داخلية وهي الألوان }
$$

• عناصر خارجية وهي الظلال والإضاءات

رابعاً: التكوينات المشتملة علي الحركة الفعلية ثلاثية الابعاد

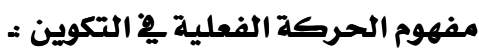

منذ بداية القرن العشرين اتخذت الفنون جميعها وخاصده فن التصميهم مفهوم الحركة

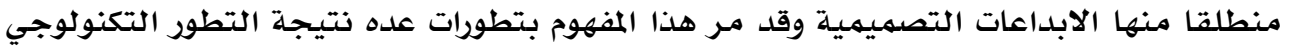
الذي اثر بـه ِِّ فن التصميهم ثلاثي الابعاد مما حقق مظاهر تشكيليه متنوعه ملفهوم الحركة

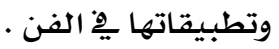


علهم الحركة "هو ذلك العلهم الذي يبحث يْ حركه الاجسام كما تحدثها القوي المؤثرة

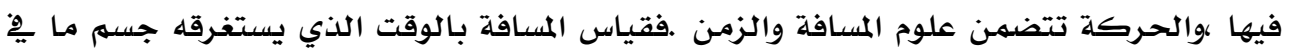

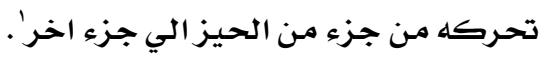

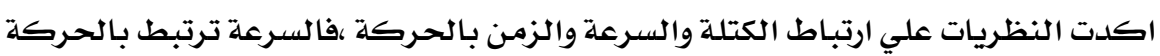

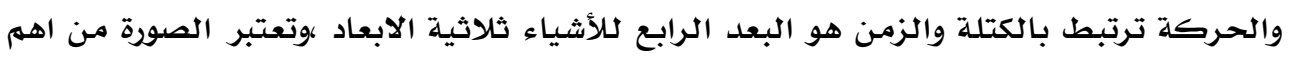

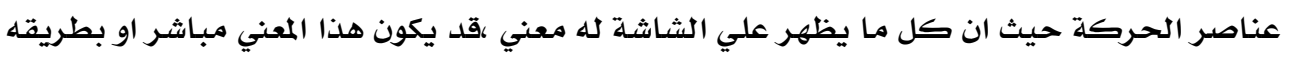

$$
\text { غير مباشره ‘. }
$$

الحركة خاصييه من خواص الكون الذي نعيث فيه ، والمتأمل لنظام الكون يجد نفسـه امـام

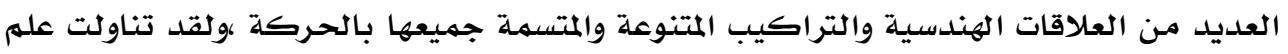

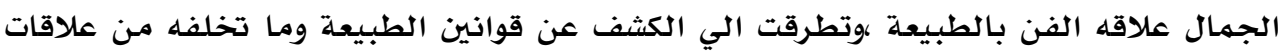

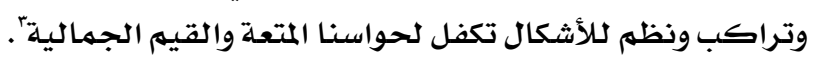
والحركة ِِّ المجال البصري هي اقوي مثيرات الانتباه فههما كانت درجه الاستغراق

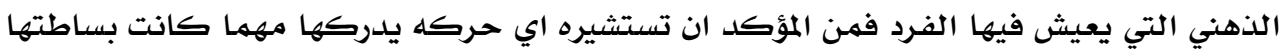

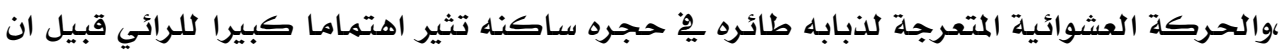
تستقر ساكنه كقبعـه سوداء علي مسطح".

لقد اصبح عنصر الحركة بارز يف اعمال فالفنانين المعاصرين تمشيا مـع روح العصر بما فيه

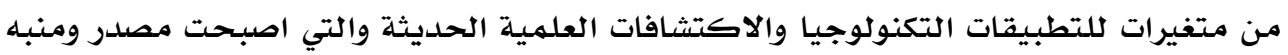

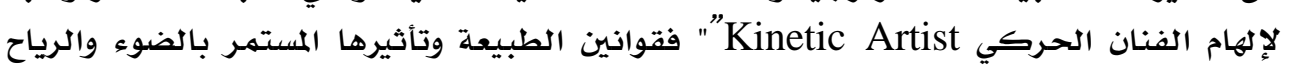

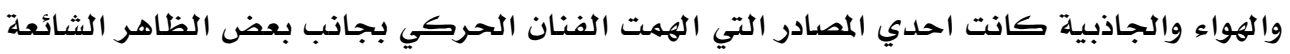

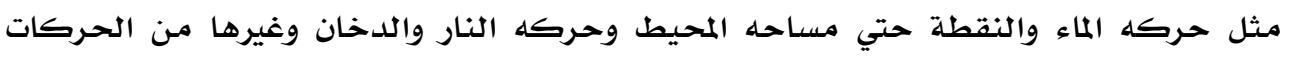
المختلفة مُثل. لقد انقسه علهم الحركة بدوره الي فرعين رئيسين يعرفان بدورهما وهما (الديناميكية ،

الاستاتيكيـ ):

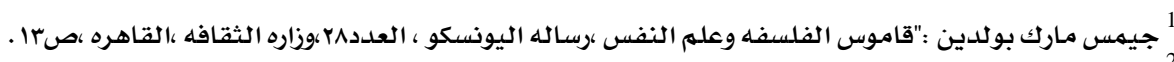

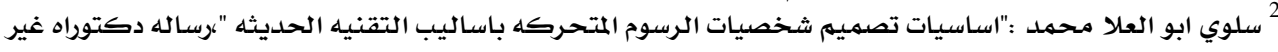

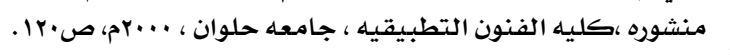

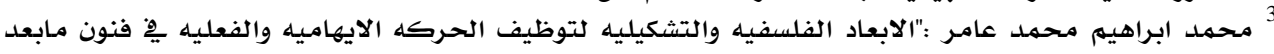

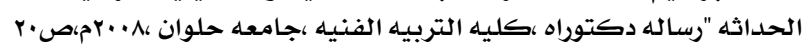

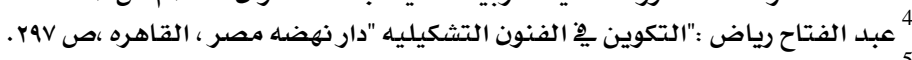

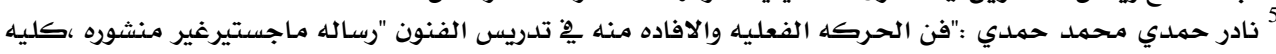

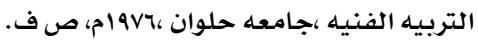




\section{اـ تعريف اللديناميكية والاستاتيكية :}

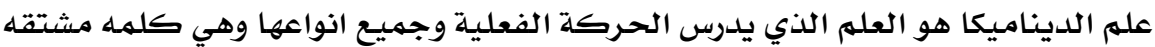

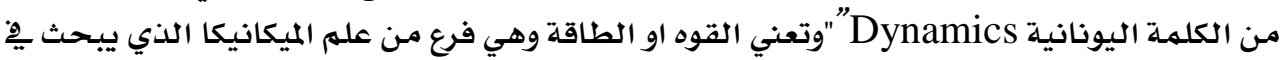

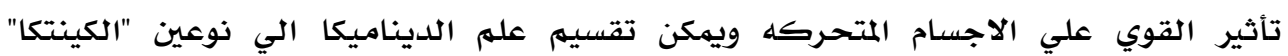

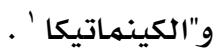
: (Kinetics )

وهي الفرع الذي يختص بالطرق التي تخلق وتعدل بها الحركة بواسطه القوي المؤثرة التي

$$
\text { تسبب التغير بِ حركيه الجسهم . }
$$

وهذا المصطلح العلمي (الكينتيكا ) قد دخل مجال الفن التشكيلي واطلق عليه اتجاه

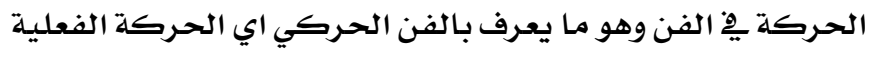

-

هي فرع الديناميكية المخفض لوصف الحركة ودراسة خصائصها.

اي ان دراسـة الخواص الهندسية العامـة لحركه الاجسام وتحديد مواضعها ومساراتها.

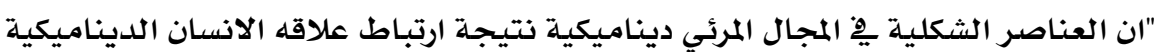

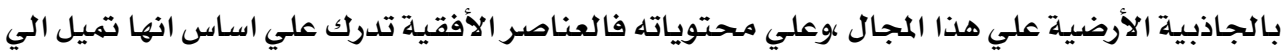

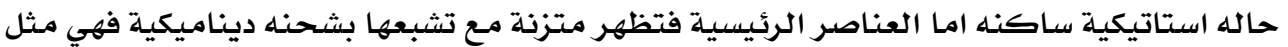
الانسان يجب ان تظل محافظه علي اتزانها.

وقد عرف نيكولا روكس Nicholas Rouks مفهوم الحركة الفعلية Kinetic Art مئ2

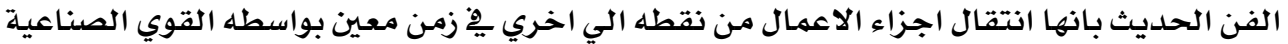
مثل المحركات والضوء الصناعي والقوي المغناطيسية والقوي الطبيعية المتمثل مِّ تيارات الهواء وغيرها' مثيل.

ويتضح ان يوجد علاقه بين الحركة والمادة والمسافة والزمن والمادة هي الوسيط سواء كان

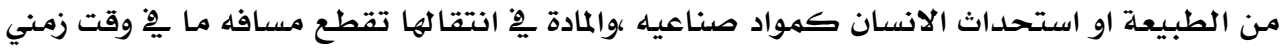
معين كما عرفت الديناميكية يْ الفن التشكيلي بانها الحركة الإيقاعية ذات النظام المتغير

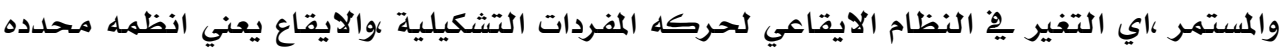
داخل الاشكال من خلال القوه وهي من مسببات الحركة المبت المتغيرة الفعلية (الديناميكية). 
الاستاتيكية : هو العلهم الذي يبحث يِّ دراسـة اتزان الاجسام او سكونها تحت تأثير القوي ' .

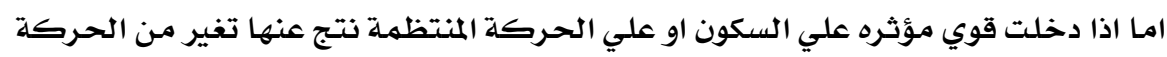

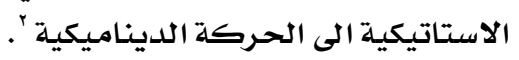

وِِّ الحقيقة ان كلا من الديناميكية والاستاتيكيه هما لفظان استعارهم الفن من العلهم

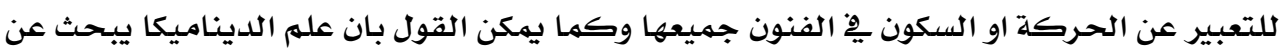
انواع كثيره من الحركة ذات البعدين ومنها ما يبحث عن الفئون الثنلاثة ابعاد .

\section{سرعه الحركة الفعلية ثلاثية الابعاد:}

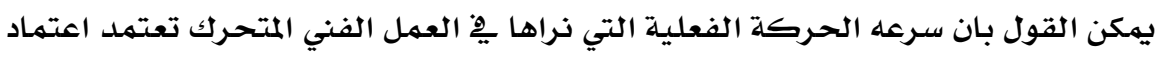

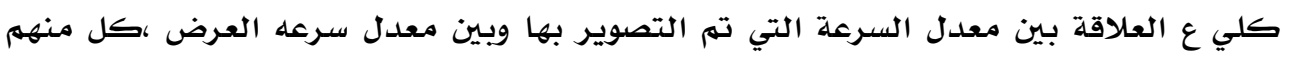

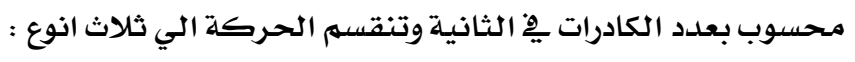

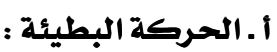

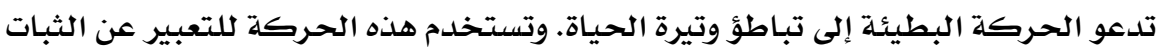

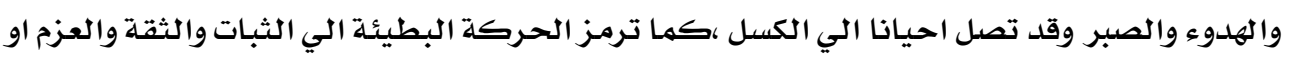

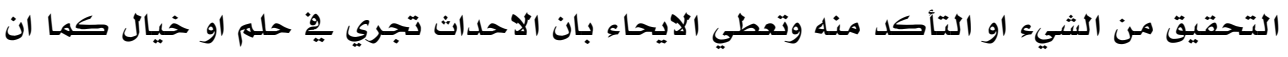

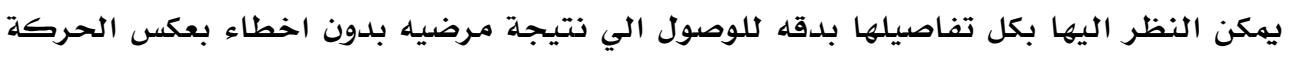

$$
\text { السريعة . المكن الفئر }
$$

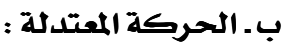
وهي ترمز الي الاعتدال الذي يبعث عن الراحة والاطمئنان فهي تأخذ المظهر العادي المألوف

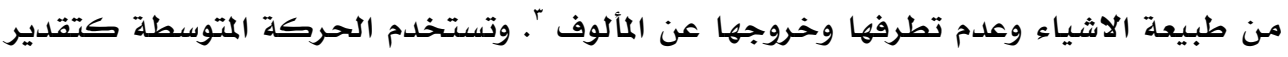

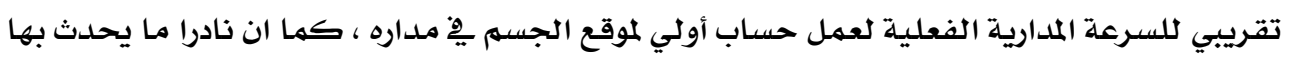
اخطاء عكس الحركات الأخرى.

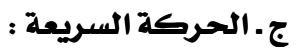

تعرف بانها النشاط الذي يبلغ الحماس فِ اي عمل فني او من خلال الامور الحياتية وهي

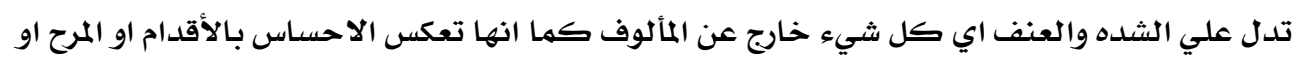

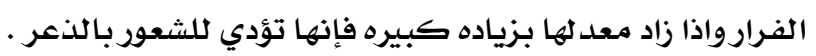

كما انها تستخدم لجعل الحدث يظهر بمظهر كوميدي من خلال جعل حركات الاتساق

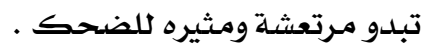

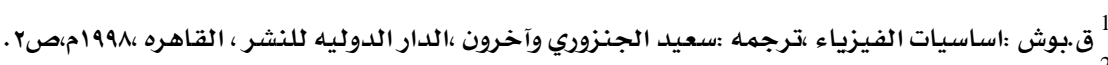

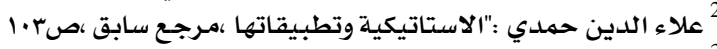

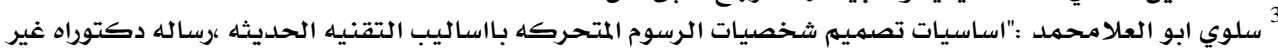

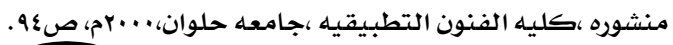




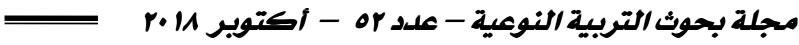

وبزياده سرعه الحركة تزداد عدد الاخطاء ويصعب بسهوله تنفيذ هذه الاخطاء الا بالتاني

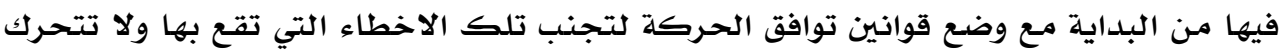

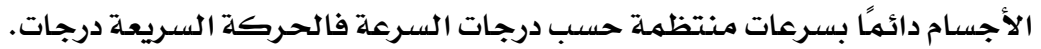

الحركة الفعلية ثلاثية الابعاد وعلاقه التغير ِِّ المسافة والزمن ·

الحركة الفعلية تتوافر بها اريعه عناصر لحدوثها (القوه ،المادة، المسافة، الزمن)فهمي تعني

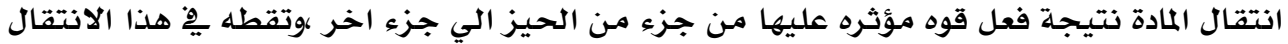

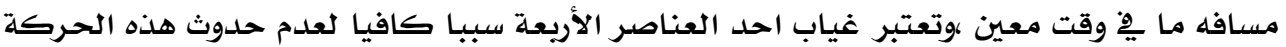
الفعلية ' مافه مال

هناك اهميه للفترة التي تستغرقها حر كاله عين المثاهد اثناء تأدية العمل الفني فهي تؤثر

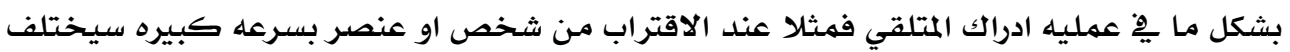

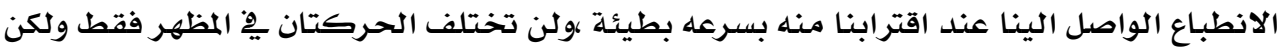

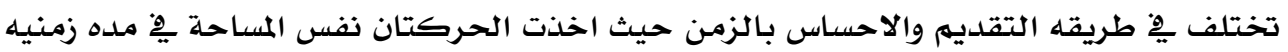

مختلفة ويهكن

$$
\text { تصنيف الحركة بطريقه اخري الي }
$$

1. حركه منتظمة

هي تلك الحركة التي يقطع فيها الجسمى مسافات متساوية يِّ ازمنـه متساويـة اي ان معادل

$$
\text { التغير يِّ المسافة ثابت ويساوي صفر. }
$$

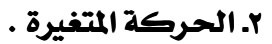

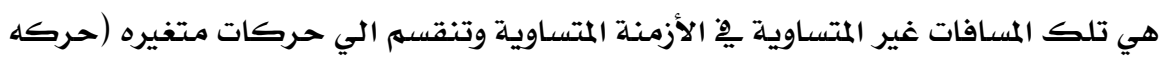

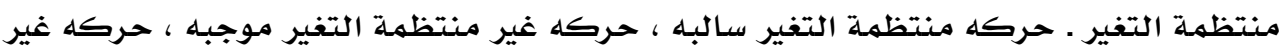

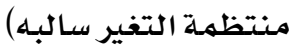

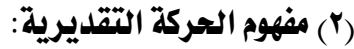

يقصد بها الاستجابات التي توحي بعامل الحركة لعناصر معينه رغم ثباتها .ويوجد ايضا.

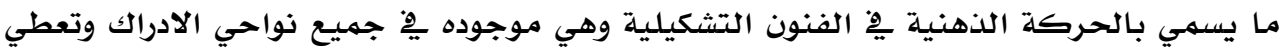

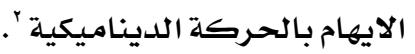

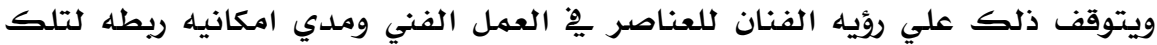

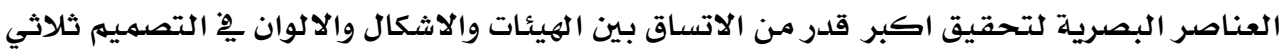

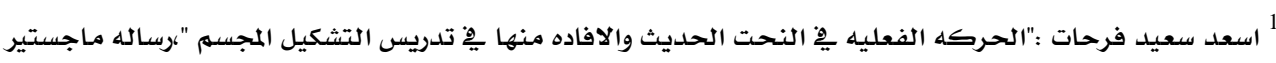

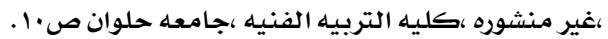

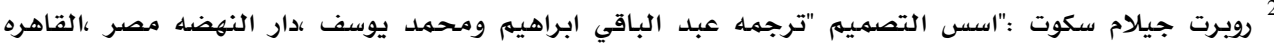




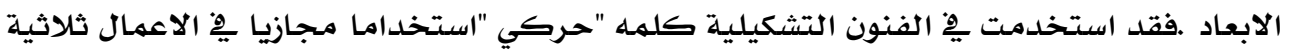

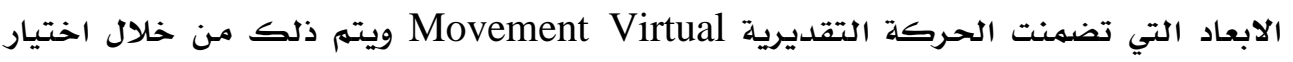

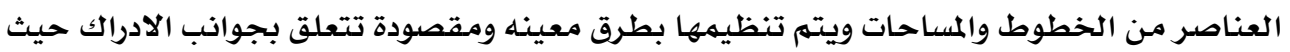

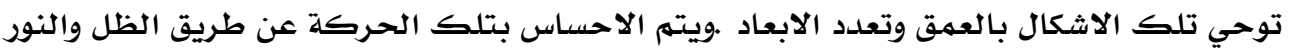

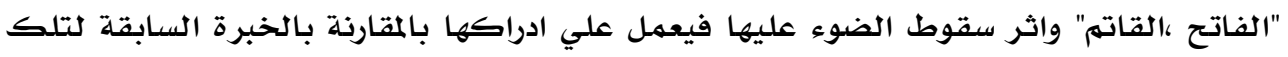

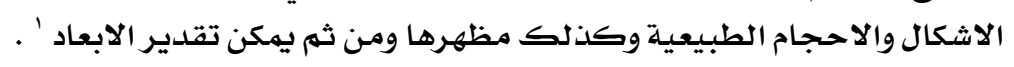

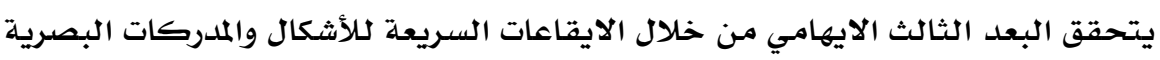

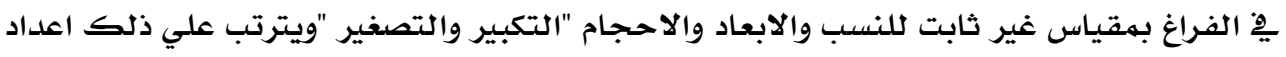

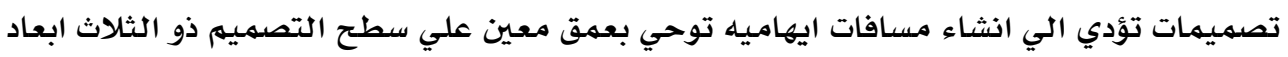

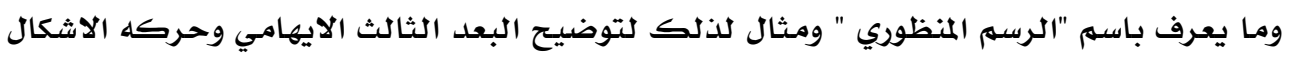
التقديرية

الحركة التقديرية Virtual Movement : الحته

اجتهد الدارسون والباحثون للوصول الي تعريف مناسب لمفهوم الحركة التقديرية اذ ان

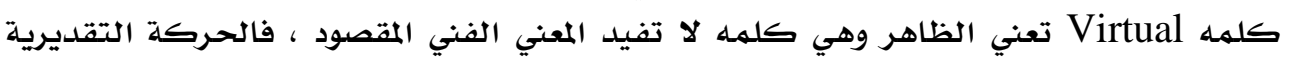

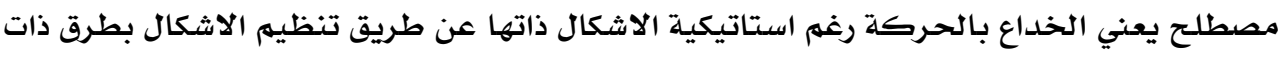

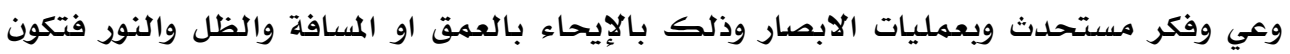

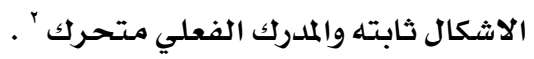

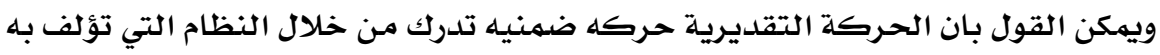

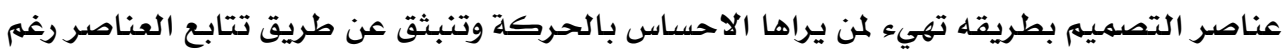
ثباتها الفعلي. كما تعرف الحركة التقديرية من الوجهة الثقافية بانها ظاهره لها وجود يِّا التراث الفني

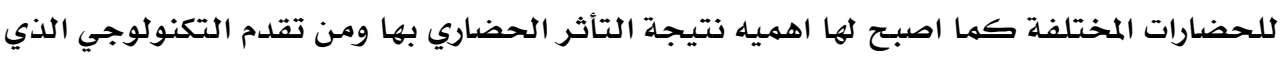

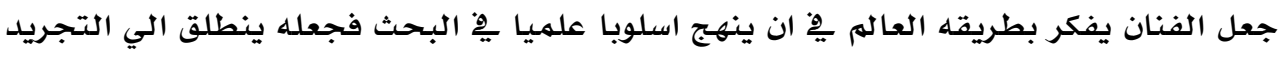

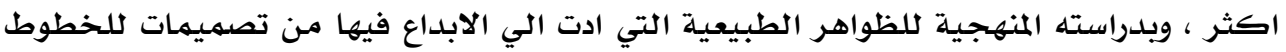

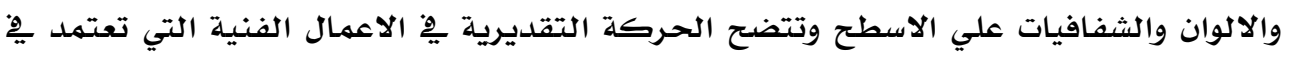

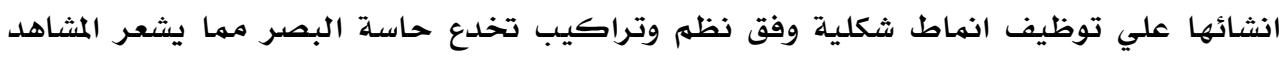
بحركية العمل رغم ثباتها ".

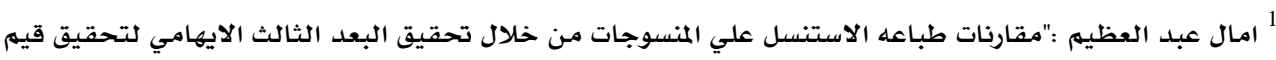

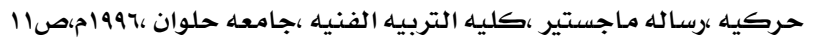

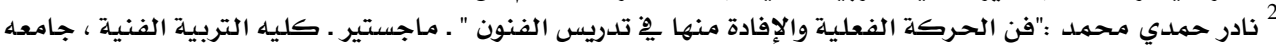

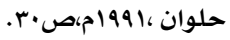

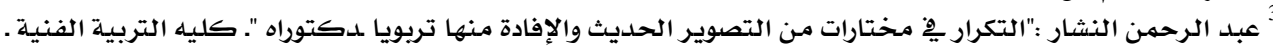

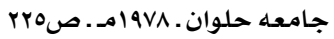


قدم عز الدين اسماعيل '.تصنيفا لكيفيات التي ظهرت بها الحركة التقديرية ِِّ الفن

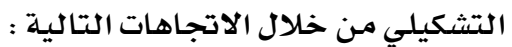

• الاول ـ اتجاه تحقيق الحركة التقديرية من خلال العناصر التمثيلية :

وهو يعني بتضمـين الحركة يْ العمل الفني اعتمادا علي اشكال وعناصر تمثل الطبيعة

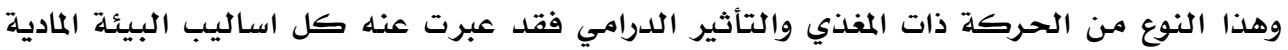

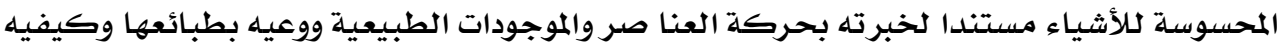

الثاني ـ اتجاه تحقيق الحركة التقديرية اعتماد علي قانون الادراك :

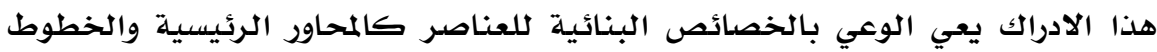

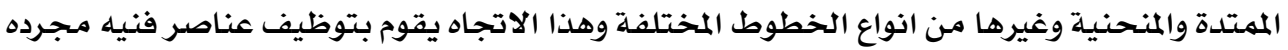

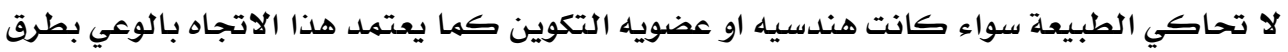

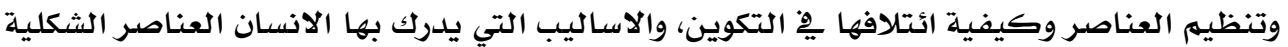

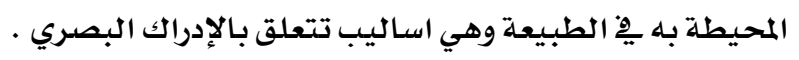

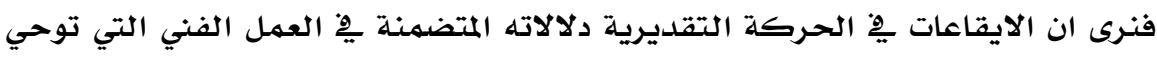

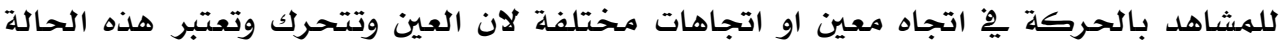

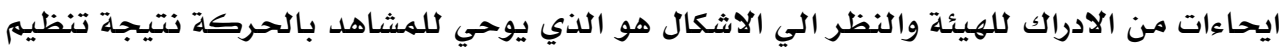

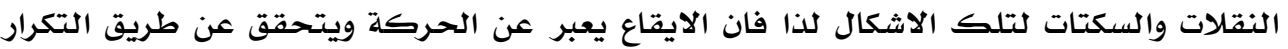

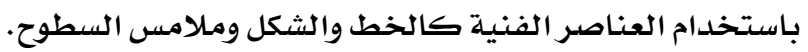

\section{نتائج الدراستة:}

للتحقق من صحة فروض الدراسة قامت الباحثة بلدراسة ا ـ ـ مفهوم البعد الثــــــالث

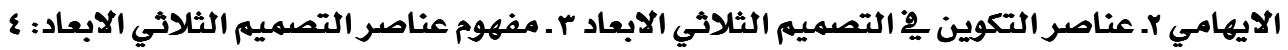
ـ التكوينات المشتملة علي الحركة الفعلية ثلاثية الابعاد وتوصلت الباحثة إلى النتائج التالية: 1 ا ـ ان البعد الثالث من المجالات التي لفتت انتباه العديد من الفنانين المحلدثين والمعاصرين المصرين والاجانب ،حيث تحول تصميمات اللوحات من سطح تمثل عليه الاشياء الي حقيقه

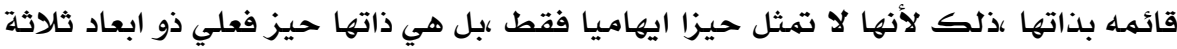
حقيقيه ץ • ان عناصر التصميهم هي مفردات لغة الشكل التي يستخدمها الفنان المصمهم وسميت بعناصر

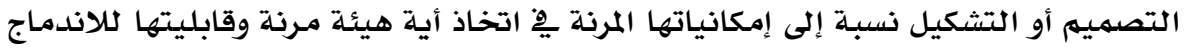

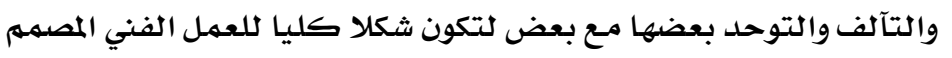


r • إن العناصر الشكلية ِِ المجال المرئي ديناميكية نتيجة ارتباط علاقه الانسان الديناميكية

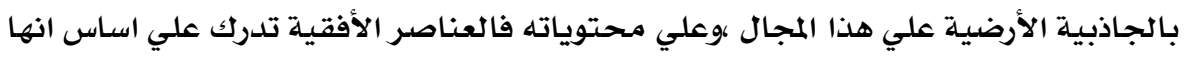

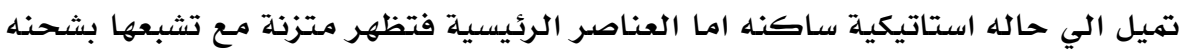

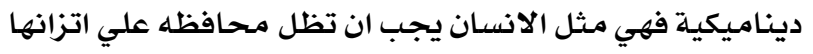
ع . ان الحركة التقديرية توحي بعامل الحركة لعناصر معينه رغم ثباتها.

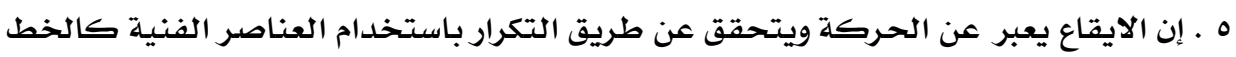

$$
\text { والشكل وملامس السطوح.. }
$$

التوصيات الاقتزهة:

1 ـ ضرورة التأكيد على دور البعد الثالث الحقيقي مـع البعد الثالث الايهامي يِّ الاعمال الفنية

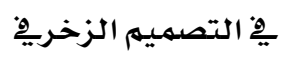

r ـ ضرورة الدعوة إلى مسايرة التطور العلمي والتعبير عن الروح الجديدة التي تمثل المقومات

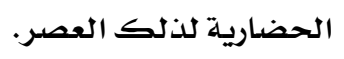

r ـ ضرورة وجود مراكز تعليمية تختص بتدريب الفنانين على التقنيات المعاصرة. ـ ـ التركيز على دور الإعلام المختص بكافة وسائله يِّ نشر أحدث ما توصل إليه العلم من تقنيات

$$
\text { تسهـم فِ الفنون. }
$$

ه ـ ضرورة تفاعل الفنانين مـع التكنولوجيا المعاصرة ومعطياتها.

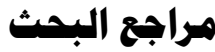

1 ـ اسعد سعيد فرحات :"الحركة الفعلية فِ النحت الحديث والإفادة منها فِ تـريس التشكيل المحسسم ، رساله

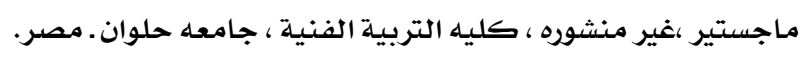

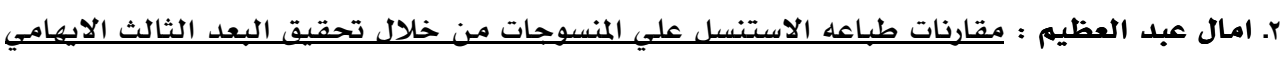

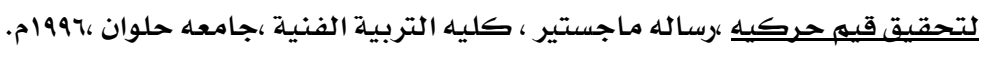

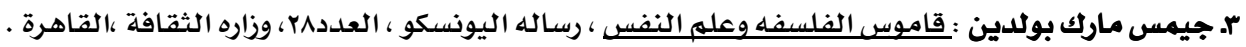

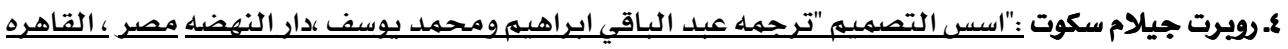

$$
\text { 0. زكريا إبراهيم: مشكلة الفن - القاهرة - مكتــة مصر - } 19197 .
$$

T. سلوي ابو العلا محمد :"اساسيـات تصميهم شخصيـات الرسوم المتحركيه باساليب التقنيه الحديثيه ،رساله

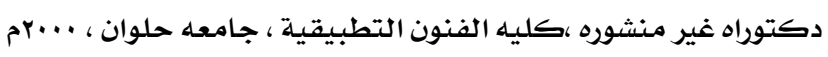

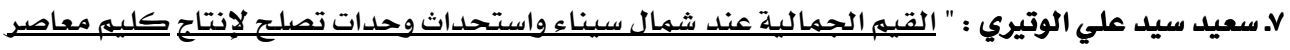

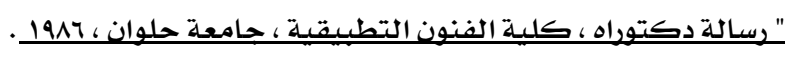

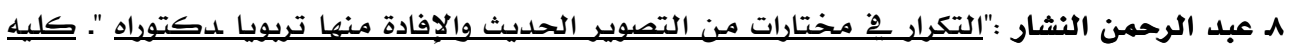
التربيـة الفنيـة ـ جامعهد حلوان. 
$\overline{\underline{\underline{2}}}$

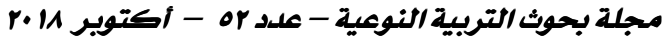

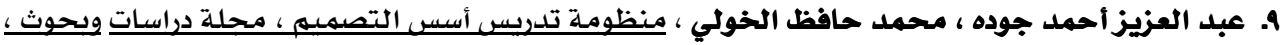

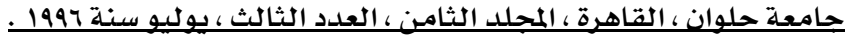

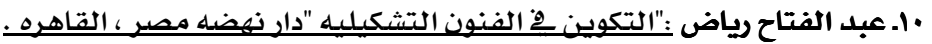

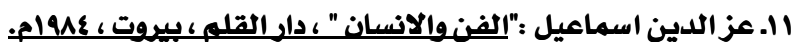

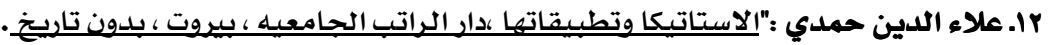
rا ـ فاروق يوسف : " أقنعة الفن" دار الفارس للنشر ، عمان ، الطبعة الأولى ، سنه 1997

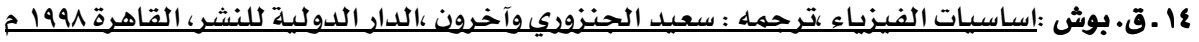
10. محمد ابراهيم محمد عامر :"الابعاد الفلسفية والتشكيلية لتوظيف الحركة الايحامية والفعلية فِفنون

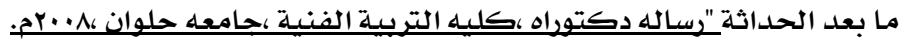
17 ـ نادر حمدي محمد :"فن الحركة الفعلية والإفادة منها فِ تدريس الفنون " ـ ماجستير ـ ـ كليه التربيدة الفنيـة ، جامعـه حلوان 1991،

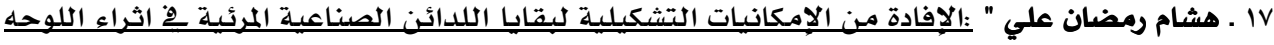

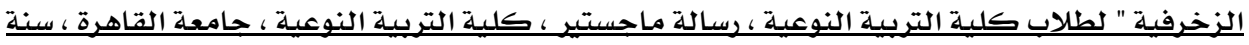
$\cdot \underline{1999}$

18 - Diana Phillips Mahoney: Modeling With Feeling - Computer Graphics World - New York - 2000

19 - http://www.alriyadh.com/2009/03/12/img/129609.jpg

20 - Renaud Blanch \& Jean Dominique: Non-Realistic Haptic Feedback For Virtual Sculpture- Pen Gun books -London - 2004

21 -Tim Anderson: The Virtual Reality - Book Case - New York - 1994

22 - Spencer Mosely and Others The Crafts design -ward swwarth publishing inc, Belmante California U.S .A .1998

23-Nicholas Rouks ; Plastic for Kinetic Art ,London, 1974.

24 - Wucius Wong, Principles of Two - Dimensional Design, Van Nostrand Reinhold Company, New York, 1972 